MERCADOLOGIA 


\title{
SIMPLICIDADE VOLUNTÁRIA E ARMÁRIO- CÁPSULA: VALORES E MOTIVAÇÕES NO CONSUMO DE VESTUÁRIO
}

\author{
VOLUNTARY SIMPLICITY AND CAPSULE-WARDROBE: \\ VALUES AND MOTIVATIONS IN CLOTHING CONSUMPTION
}

Érica Maria Calíope Sobreira

Universidade Federal do Ceará

Áurio Lúcio Leocádio da Silva Universidade Federal do Ceará

Pedro Felipe da Costa Coelho Universidade Federal do Ceará

\section{Data de submissão: 22 dez. 2017 . Data de aprovação: \\ 16 abr. 2018 . Sistema de avaliação: Double blind review. Universidade FUMEC / FACE. Prof. Dr. Henrique Cordeiro Martins. Prof. Dr. Cid Gonçalves Filho.}

\section{RESUMO}

O objetivo deste estudo foi analisar aspectos da Simplicidade Voluntária (SV) no processo de adoção do conceito do Armário-Cápsula (AC) pelo público feminino. Em uma abordagem exploratória e qualitativa, foram feitas entrevistas semiestruturadas com 13 adeptas do conceito. Os dados foram analisados segundo a Análise de Conteúdo. Os valores de SV preponderantes para a adoção do AC foram: foco no self e consciência ecológica. O conceito é adaptável, sem um número fixo de peças e intervalo de tempo de 3 meses. Percebeu-se a valorização do consumo de experiências. Tendências de consumo da SV foram incorporadas pelas entrevistadas, além dos seguintes valores: foco na sociedade, consciência ecológica, foco no self, foco nos relacionamentos, simplicidade material.

\section{PALAVRAS-CHAVE}

Resistência ao Consumo. Simplicidade Voluntária.Armário-Cápsula. Consumo de Vestuário. Público feminino. 


\section{ABSTRACT}

The objective of this study was to analyze aspects of voluntary simplicity (VS) in the adoption process of the capsule-wardrobe concept (CW) for women. In an exploratory and qualitative approach, semi-structured interviews were conducted with 13 followers of the concept.The data was analyzed according to the Content Analysis. The preponderant VS values for the CW adoption were: self and ecological awareness. The concept is adaptable, without a fixed number of items and time interval of 3 months. Consumption experiences were appreciated. Trends of VS consumption were incorporated by the interviewees, in addition to the values: society, ecological awareness, self, relationships, material simplicity.

\section{KEYWORDS}

Consumption Resistance. Voluntary Simplicity. Capsule-Wardrobe. Clothing Consumption. Female Audience.

\section{INTRODUÇÃO}

A busca pela satisfação por meio do consumo excessivo vem levando uma parcela da sociedade, paradoxalmente, a ficar insatisfeita com o seu estilo de vida (BAUMAN, 2008). Associado a isso, a estreita relação entre as mudanças climáticas e os elevados padrões de consumo da sociedade atual levou grupos de consumidores a constituírem movimentos de resistência ao consumo que atingem as escolhas de estilo de vida (CHAUVEL et al., 20I5). Tais movimentos são caracterizados pela ênfase na adoção de hábitos de consumo mais simples e atrelados a crenças éticas ou espirituais (IYER; MUNCY, 2009). Entre as variações possíveis para estes movimentos, destacam-se o consumo verde, as comunidades antimarcas e a simplicidade voluntária (KOZINETS; HANDELMAN; LEE, 20I0), temas que ainda vem sendo pouco explorados por pesquisadores de consumo (SUAREZ; CHAUVEL; CASOTTI, 20I2).

Especificamente sobre a simplicidade voluntária, trata-se de um estilo de vida baseado no baixo consumo, responsabilidade ecológica e autossuficiência (ELGIN, 1993), onde se rejeita o materialismo e o estilo de vida consumista com o intuito de consumir apenas o que é necessário (ALEXANDER et al., 2009; ZAVESTOSKI, 2002). Viver com o essencial, porém, não significa pobreza ou privação, mas está relacionado à satisfação pessoal advinda da decisão voluntária de consumir apenas o que é suficiente, mesmo quando o indivíduo possui condição financeira para consumir mais (ETZIONI, 1999).

No Brasil, recentes estudos analisaram o consumo consciente (BARROS et al. 2009; MONTEIRO et al., 2008; SOUZA; CASOTTI; LEMOS, 20I3; TONI; LARENTIS; MATTIA, 20I2; TRINDADE; AYROSA; SAUERBRONN, 20I5), as motivações para adotar a simplicidade voluntária (HOR-MEYLL; SILVA, 2016), o consumo responsável de membros de uma ecovila (BORELLI, 20I4), o impacto do materialismo na simplicidade voluntária (FERRAZ et al., 2014) e a rela- 
ção do "eu estendido" com a simplicidade voluntária (AQUINO, 2016). Contudo, Elgin (1993) afirma que a perspectiva de redução do consumo pessoal também está relacionada ao modo de se vestir, na qual roupas mais funcionais, duráveis e estéticas são priorizadas. A opção por esse tipo de roupas, no entanto, não significa não ter um estilo ou negar uma forma de autoexpressão através das roupas usadas (SOPER, 2008). Na verdade, é uma forma de rejeição ao fast fashion, caracterizado pela resposta rápida às últimas tendências de moda em um modelo de negócio com permanente rotatividade de produtos (BYUN; STERNQUIST, 20I I).

Atrelada a essa perspectiva, o conceito de capsule-wardrobe (armário-cápsula) tem sido difundido e recebido positivamente tanto por especialistas em moda como por consumidores mais conscientes (KUMAR; VACCARO, 2017). O armário-cápsula é uma pequena coleção de roupas agrupadas de modo a compor uma cápsula - um guarda-roupa compacto - com peças de alta qualidade, longa durabilidade e em quantidade limitada que seriam usadas a cada estação (DOUGHER, 20I5), em especial pelas mulheres, que são as principais adeptas do conceito (HEGER, 20 I6).

A despeito do interesse de consumidoras brasileiras em adotar este conceito, existe uma lacuna de pesquisa relacionada ao estudo do armário-cápsula na perspectiva de aliar simplicidade, redução de consumo e estilo de vida (HEGER, 20 I6). Nesse contexto, esta pesquisa tem como objetivo analisar os aspectos da simplicidade voluntária no processo de adoção do conceito do armário-cápsula pelo público feminino.

Considerou-se para o desenvolvimento deste estudo, portanto, que o vestir-se pode ser uma declaração externa de simplicidade, por meio de um esforço voluntário para expressar esteticamente a oposição à cultura de consumo (AUDET; SAFADI, 2004). Também foi considerado que mulheres são mais conhecidas do que homens por experimentarem o conceito de guarda-roupa minimalista (HEGER, 20I6), o que justifica a escolha deste público para a condução do estudo. Em função da temática abordada e do objetivo deste estudo, o referencial teórico a seguir trará definições e valores da simplicidade voluntária, bem como a sua influência para o comportamento de consumo de seus adeptos.

\section{SIMPLICIDADE VOLUNTÁRIA: FUNDAMENTOS, VALORES E MOTIVAÇÕES}

A simplicidade voluntária (SV) é um modo de viver onde se busca o distanciamento do supérfluo e da vida agitada em prol de um estilo de vida simples (ELGIN, 2010). Para Luhrs (2002) esse estilo de vida é uma forma de ganhar tempo para si mesmo em um mundo agitado. Shi (1985) afirma que uma "vida simples" é praticamente tão difícil de ser definida quanto de ser vivida, de maneira que o seu significado nunca foi precisamente fixado, embora a sua representação, de acordo com Gambrel e Cafaro (2010), sempre estivesse associada a um conjunto de mudanças de sentimentos, ideias e atividades, inclusive nas práticas de consumo.

A opção por viver de forma simples deve ser uma escolha voluntária, portanto não se caracteriza simplicidade voluntária como uma escolha motivada por falta de condições financeiras, ou uma escolha associada a sensações de privações no consumo (ETZIONI, 1999).A simplicidade voluntária 
também não possui normas específicas, líderes oficiais, não recruta formalmente seus membros e não é organizada de modo hierarquizado (GRIGSBY, 2004), mas supõe a possibilidade de um indivíduo viver de forma mais significativa, com mais liberdade e felicidade, através de um consumo justo e sustentável (GAMBREL; CAFARO, 20I0; SILVA, 20I3).

Segal (1999) afirma que viver de forma simples é uma conquista que pode surgir da submissão da dimensão material em prol de uma visão ampla de desenvolvimento pessoal, promovida pela criação de uma vida rica nas dimensões estética, social e espiritual. Especificamente sobre a perspectiva espiritual, a simplicidade voluntária está relacionada ao investimento de tempo e energia no desenvolvimento do seu eu interior (PIERCE, 2000).

Em relação às dimensões da simplicidade voluntária, Elgin e Mitchell (1977) apresentaram cinco valores que podem constituir motivações para a adoção do estilo de vida simples: (a) simplicidade material: comprar o necessário e reduzir excessos; (b) escala humana: preferir menos produtos e instituições menores e mais eficientes; (c) autodeterminação: maior controle pessoal e autossuficiência, de forma que os indivíduos se tornem menos dependentes das organizações; (d) consciência ecológica: preocupação com conservação dos recursos do planeta, levando à responsabilidade ecológica; e (e) crescimento pessoal: através da busca pelo desenvolvimento espiritual, algo ligado à 'vida interior'. Elgin (20I2) ainda propõe outras dimensões para um simplificador: emocional (zelo aos relacionamentos) e mental (buscar aprender continuamente).

Johnston e Burton (2003), por sua vez, destacam quatro motivações para a adoção da simplicidade voluntária: (i) foco no self: busca pela independência sobre suas escolhas e ações; busca por valores essenciais, propósito e satisfação de vida, desejo de crescimento pessoal; (ii) foco nos relacionamentos: decisão de simplificar a vida e abrir espaço para uma maior dedicação à família, amigos e comunidade; (iii) foco na sociedade: relacionado ao processo de redução dos níveis de consumo, considerando que as escolhas individuais geram impactos para a sociedade; e (iv) foco na terra: busca de experiências mais próximas da natureza (acampar, caminhar).

A simplicidade voluntária é vista como diretamente oposta ao paradigma do excesso, estando, dessa forma, associada às discussões sobre a redução nos níveis de consumo das pessoas (BARTON, 2015). Existe um novo grupo de consumidores interessados em reduzir a quantidade de produtos que consomem de forma voluntária a despeito daqueles que, recentemente inseridos na sociedade de consumo, têm interesse em adquirir cada vez mais novos produtos (JOHNSTON; BURTON, 2003; SHAW; NEWHOLM, 2002).

Consumidores simplifiers (simplificadores) são aqueles que adotam a simplicidade voluntária, buscando reduzir o seu nível de consumo e adotar hábitos de consumo mais simples. Para eles, consumir o que é essencial pode estar relacionado à busca de uma vida mais feliz e ao exercício prático de suas crenças éticas ou espirituais (IYER; MUNCY, 2009; KOZINETS; HANDELMAN; LEE, 20I0). Apesar de estarem inseridos num ambiente materialista, tais consumidores se vinculam aos demais grupos de indivíduos que adotam práticas de redução do consumo ou de anticonsumo 
(NEPOMUCENO, 20I2) e, na maioria dos casos, optam por reduzir o consumo pessoal ao "necessário" (BEKIN; CARRIGAN; SZMIGIN, 2005). Segundo Silva (20I3), eles valorizam mais o consumo de experiências e de serviços (viagens, cinema, restaurantes, atividades culturais) do que o consumo de bens materiais.

De fato, a simplicidade voluntária é um estilo de vida capaz de influenciar os padrões de consumo e as decisões de compra de seus adeptos (SHAMA, 198I) e se fundamenta na crença de que a cultura de consumo dominante é a responsável pelo o excesso de consumo dos indivíduos. Esta cultura estimula $\circ$ materialismo, a competição e a destruição do planeta. Neste contexto, a vida simples se mostra como alternativa de uma vida mais gratificante, ancorada em práticas de consumo mais justas e sustentáveis (GRIGSBY, 2004) e na busca pela minimização de impactos ecológicos através da redução do consumo (EHRLICH; EHRLICH, 1990).

Porém, a simplicidade voluntária não se caracteriza como ascética, isto é, de austeridade rigorosa, mas como estética, pois cada pessoa é responsável pela maneira com que o seu nível e padrão de consumo podem afetar o meio ambiente, e, dessa forma, buscar ajustá-los na sua vida prática sem maiores prejuízos ao planeta (ELGIN, 20I2). O movimento representa a expressão de negação intencional do materialismo e está intimamente ligado ao grau de esforço definido pelo indivíduo para maximizar o controle de suas atividades rotineiras e minimizar seus níveis de consumo (MCDONALD et al. 2006), inclusive no consumo de vestuário (AUDET; SAFADI, 2004).

O consumo de vestuário dos simpli- ficadores contraria o fast fashion, modelo que leva à obsolescência de produtos, rapidamente renovados em coleções que refletem as últimas tendências da moda (BYUN; STERNQUIST, 20II). Aqueles que vivem de forma simples tendem a se vestir mais informalmente, optando por roupas funcionais e mais duráveis (ALEXANDER, 20II). Os simplificadores preferem produtos usados ou reciclados, apresentam orientação do tipo "faça você mesmo", pois buscam reutilizar e customizar peças, além de comprar em brechós e preferir a doação como forma de descarte (BALLANTINE; CREERY, 20I0; ELGIN, 20I2; SHAMA, I 98I; SILVA, 20I3).

Dessa forma, supõe-se que o conceito do armário-cápsula (AC) está intrinsecamente relacionado ao consumo de vestuário de adeptos da simplicidade voluntária. O tópico seguinte irá tratar do conceito do armário-cápsula, objeto deste estudo.

\section{Conceito do armário-cápsula}

O armário-cápsula foi popularizado por Caroline Rector, autora do blog do Un-fancy, em 20I5. Porém, este termo foi adotado inicialmente na década de 1970, por uma empresária de Londres proprietária de uma boutique fashion. De acordo a blogueira norte-americana, o armário-cápsula é uma pequena coleção de roupas sazonais, compondo uma cápsula com peças de alta qualidade, longa durabilidade, em quantidade limitada (DOUGHER, 20I5). O foco do conceito está na sua composição: feita de peças versáteis que reflitam o estilo pessoal de cada indivíduo (RECTOR, 2014) e proponham a essência da simplicidade, normalidade e serenidade combinadas (KARG, 20I5).

As orientações para a adoção do conceito 
definidas por Caroline Rector são: I) separar as roupas em 37 peças; 2) usar as 37 peças por três meses; 3) não comprar nada novo durante os três meses; 4) planejar e realizar compras para o próximo armário-cápsula nas últimas duas semanas dos três meses; 5) a quantidade das próximas compras depende do indivíduo, contanto que ele lembre que menos é mais (HEGER, 2016). Sugere-se que, de preferência, as próximas compras sejam voltadas para a substituição de peças ou para a renovação do estilo pessoal para a próxima cápsula (PUCCINI; ROBIC, 20I5).

\section{METODOLOGIA}

Para alcançar o objetivo deste estudo, realizou-se uma pesquisa exploratória de caráter qualitativo (MERRIAM, 2009). Os dados foram coletados por meio de treze entrevistas semiestruturadas com adeptas do armário-cápsula. $O$ roteiro de entrevista foi dividido em questões relativas ao estilo de vida de simplicidade voluntária, motivações e o processo de adoção do armário-cápsula, além de questões sobre o perfil demográfico das entrevistadas.

O contato inicial com as entrevistadas, assim como o convite para a participação na pesquisa, se deu em três grupos do Facebook sobre o armário-cápsula. Duas participantes manifestaram espontaneamente $o$ interesse em participar da pesquisa e as demais foram convidadas para participar deste estudo através de mensagens privadas. $O$ perfil das entrevistadas se encontra no Quadro I, onde as respondentes são nomeadas por pseudônimos atrelados ao seu perfil:

A partir do Quadro I, percebe-se que as entrevistadas são, em sua maioria, mulheres solteiras, que possuem entre 18 e 32 anos e residem em diferentes regiões do país. A aplicação das entrevistas se deu entre maio e junho de 2017 via Skype ou Facebook. Os diálogos foram gravados e transcritos para posterior análise de dados. As entrevistas duraram vinte e um minutos em média, totalizando quatro horas e meia de gravação e oitenta páginas de depoimentos. Dentre as dificuldades para a coleta de dados, destaca-se que, em alguns momentos, os diálogos foram interrompidos em função de falhas na conexão.

Por fim, a análise dos dados foi feita através da análise de conteúdo proposta por

QUADRO 1 - Perfil das entrevistadas

\begin{tabular}{|c|c|c|c|c|}
\hline Pseudônimo & Idade & Ocupação & Estado civil & Cidade \\
\hline A espontânea & 27 & Jornalista & Casada & Salvador (BA) \\
\hline A planejadora & 27 & Publicitária & Solteira & São Paulo (SP) \\
\hline A viajante & 32 & Professora de inglês & Solteira & Salvador (BA) \\
\hline A autorreflexiva & 18 & Estudante de Arquitetura & Solteira & Presidente Prudente (SP) \\
\hline A pragmática & 30 & Engenheira Florestal & Solteira & Rio de Janeiro (RJ) \\
\hline A politizada & 21 & Estudante de Antropologia & Solteira & Belo Horizonte (MG) \\
\hline A equilibrada & 25 & Diretora de Arte e Publicidade & Casada & Novo Hamburgo (RS) \\
\hline A madura & 19 & Estudante de Psicologia & Solteira & Parnaíba (PI) \\
\hline A criteriosa & 28 & Social Mídia & Solteira & São Paulo (SP) \\
\hline A decidida & 21 & Estudante de Eng. de Produção & União estável & Salvador (BA) \\
\hline A detalhista & 25 & Médica & Solteira & São Paulo (SP) \\
\hline A empolgada & 23 & Cozinheira e Maquiadora & Solteira & São Paulo (SP) \\
\hline A desorganizada & 27 & Estudante de Psicologia & Solteira & Salvador (BA) \\
\hline
\end{tabular}

Fonte: Elaborado pelos autores (2017). 
Bardin (20II). Optou-se pela técnica de análise categorial, a qual funciona por meio de "operações de desmembramento do texto em unidades, em categorias segundo reagrupamentos analógicos" (BARDIN, 20II, p. 20I). Nessa lógica, as transcrições das entrevistas foram codificadas, agrupadas, categorizadas, associadas à literatura utilizada neste estudo e resultaram nos subtópicos da seção seguinte.

\section{ANÁLISE DOS RESULTADOS}

Este tópico traz a análise dos principais achados deste estudo. Primeiro, as motivações para a adoção do armário-cápsula serão discutidas. Em seguida, o processo de adoção do conceito será abordado, por fim, o significado da simplicidade para as entrevistadas. Os tópicos abaixo não foram previamente estabelecidos e derivam do processo de análise de conteúdo.

\section{Motivações para a adoção do armário-cápsula}

Dentre as razões para adotar o conceito, a categoria "O olhar do outro" evidenciou o desejo das entrevistadas de serem menos pressionadas por colegas e amigos no que diz respeito a sua exposição pessoal por utilizar roupas já usadas em outras ocasiões, a exemplo de situações em que postam fotos nas redes sociais. A seguir, alguns depoimentos:

[...] antes de eu conhecer o armáriocápsula, eu era uma pessoa muito daquelas que "ai, eu não vou usar essa roupa porque me viram com essa roupa semana passada" (A autoreflexiva).

Hoje com rede social, você tira uma foto hoje com uma roupa e amanhã você não quer usar de novo (A viajante).

Os resultados indicam que as pressões sociais sofridas pelas entrevistadas as levaram a buscar formas de consumo mais simples, capazes de fortalecer a sua autonomia na tomada de decisões de compra e de proporcionar uma maior sensação de liberdade ao adotar um conceito segundo o qual poderiam se sentir apoiadas quanto ao uso de roupas repetidas, diminuindo a sensação de preocupação com o julgamento das pessoas sobre o seu vestuário. Outra pressão contestada foi proveniente da indústria da moda, como identificado na categoria "A influência da moda". As entrevistadas afirmaram que, antes de adotarem - conceito do armário-cápsula, estavam comprando e utilizando peças que estavam na moda, mas que, depois de pouco tempo, não as serviam mais. Os seguintes relatos ilustram essa afirmação:

Eu tava comprando roupas que tavam na moda, mas eu seguiria a moda e ia comprar um jeans rasgado. Eu nem me vejo com um jeans rasgado (A espontânea).

Antes eu tinha uma mentalidade muito pequena de achar que se porque estão usando, porque está na moda, eu teria que usar também ( $A$ criteriosa).

A categoria "Identidade" revelou que a utilização das peças que eram rapidamente substituídas, inclusive, levou parte das entrevistadas a não se sentirem representadas pelas roupas que estavam consumindo, elas não se identificavam com suas peças. Outra motivação para a adoção do conceito foi identificada na categoria "Repensar o consumo”, a qual representou a insatisfação das entrevistadas ao perceberem que os itens disponíveis no guarda-roupa eram frutos do consumismo.

Eu não sentia que minhas roupas me representavam, então foi o que mais me chamou a atenção (A madura). 
Primeiro foi repensar um pouco. Foi até isso que me deu vontade de ter o armáriocápsula, de ter uma vida minimalista, é essa questão do consumismo (A viajante).

Acho que a consciência de consumo, assim, que a gente não precisa de muito para viver bem (A planejadora).

Segundo a categoria "Espaço", uma questão de ordem prática também motivou a adoção do conceito: a falta de espaço no guarda-roupa. $O$ excesso de roupas, calçados e acessórios levou as entrevistadas a ficarem sem espaço para guardá-las, gerando a necessidade de otimização do espaço disponível, como se observa:

Falta de espaço. Meu guarda-roupa é pequeno, é duas portas. E o que acontece: ele é duas portas pra duas pessoas. Então, assim, difícil, né? (A espontânea).

As adeptas do armário-cápsula tomaram a decisão de adotar o conceito com motivações diversas. A busca pela autonomia nas decisões de compra, por exemplo, foi manifestada na oposição às pressões da indústria da moda e dos amigos. As consumidoras afirmaram que estavam cansadas de comprar novas roupas como forma de darem uma resposta aos outros, além de utilizarem as peças por um período curto só porque estavam na moda. Nesta ótica, Silva (20 I3) afirma que a necessidade de liberdade em relação a essas pressões seria uma das razões que levariam um indivíduo a aderir à simplicidade voluntária, pela possibilidade de proporcionar a ele um viver mais significativo, com mais liberdade e felicidade (GAMBREL; CAFARO, 20I0). Ao que tudo indica, as entrevistadas sentiram a necessidade de retomar a independência sobre escolhas e ações através da busca pela liberdade em relação às pressões sofridas, característica típica do valor foco no self, de Johnston e Burton (2003).

Também foi mencionado que os itens que estavam no guarda-roupa das entrevistadas não tinham um significado positivo, pois não as representavam, além de ocuparem excessivo espaço. A necessidade de repensar o consumo, através da insatisfação com o consumismo, sugere que as adeptas do armário-cápsula refletiram sobre uma cultura de consumo que estimula 0 consumo excessivo dos indivíduos (GRIGSBY, 2004), e, assim como os simplificadores, optaram por uma alternativa de consumo mais simples e reducionista (JOHNSTON; BURTON, 2003; SHAW; NEWHOLM, 2002). Ao que parece, associada a essa necessidade, também uma maior consciência ecológica em relação aos impactos promovidos por seus padrões de consumo, inicialmente, consumistas, noção compatível com o valor consciência ecológica de Elgin e Michell (1977). O quadro a seguir resume as motivações encontradas:

QUADRO 2 - Motivações para a adoção do conceito do armário-cápsula

\begin{tabular}{|c|l|}
\hline Categorias & \multicolumn{1}{|c|}{ Motivações } \\
\hline O olhar do outro & $\begin{array}{l}\text { Preocupação com o julgamento das pessoas sobre o seu vestuário, gerando necessidade de liber- } \\
\text { dade dessa pressão }\end{array}$ \\
\hline A influência da moda & $\begin{array}{l}\text { Sentiam-se pressionadas a comprar e usar peças que estavam na moda, gerando necessidade de } \\
\text { liberdade dessa pressão }\end{array}$ \\
\hline Identidade & Não se sentiam representadas pelas roupas que estavam consumindo \\
\hline Repensar o consumo & Insatisfação com peças compradas como frutos do consumismo \\
\hline Espaço & Falta de espaço no guarda-roupa, gerando necessidade de otimização \\
\hline
\end{tabular}

Fonte: Elaborado pelos autores (2017). 


\section{A adoção do conceito}

As entrevistadas conheceram o conceito do armário-cápsula através de um fenômeno sócio midiático, ou seja, através de blogs, grupos de Facebook, canais do Youtube, além do livro "A mágica da arrumação".

Quanto à adoção, foi constatado que a elaboração do armário e a sua utilização, pelas entrevistadas, foram flexíveis, de acordo com a categoria "Adaptabilidade", a qual tem relação com elementos que compõe o conceito: a quantidade de peças, o período de duração e a divisão pelas estações. As entrevistadas adaptaram o armário às suas necessidades, sem um estabelecimento numérico fixo de peças ou um intervalo de tempo fixo de três meses para a duração da cápsula, como o sugerido pela principal difusora do conceito, Caroline Rector. As respondentes utilizam armários anuais, semestrais ou trimestrais, com um número de peças considerado suficiente por elas, desde que o foco seja reduzir a quantidade dos itens e seja dada ênfase à usabilidade das peças e ao seu bem-estar. Além disso, algumas entrevistadas enxergam o armário-cápsula como uma mala de roupas, por se tratar de um conceito, não um guarda-roupa convencional:

[...] eu consegui montar um armáriocápsula com sessenta e oito itens e ele é atemporal. Então, ele é pra minha vida, para o ano inteiro (A empolgada).

Ele tá completo, verão, inverno... e eu não contei as peças, eu só tô vivendo com uma mala, e eu considerei isso um armário-cápsula (A detalhista).

O armário-cápsula não se limita a uma coleção de roupas sazonais, como Dougher (20I5) defende, visto que, para algumas adotantes ele é composto para três, seis ou doze meses. Além disso, o conceito também foi adotado por entrevistadas que residem em regiões onde as estações do ano não são bem definidas, conforme o trecho em destaque:

[...] eu moro no nordeste, aqui não tem as estações definidas, então eu ainda tenho que ver como vai ser esse processo [...] (A madura).

A gestão do armário-cápsula, no que diz respeito à reposição de peças, ocorre de maneira semelhante ao apontado por Puccini e Robic (20I5), ou seja, por meio da compra de itens apenas para substituir outras peças. A categoria "Tendências de Consumo" apresentou os seguintes hábitos associados à adoção do conceito: preferência por reutilizar e customizar peças, comprar itens em brechós, trocar peças entre amigas, procurar ter menos coisas, comprar pouco e melhor, e doar peças. Alguns trechos ilustrativos:

Eu sempre tento reutilizar. Tipo, uma calça que rasga, eu faço um short ou alguma coisa assim (A autoreflexiva).

[...] eu acho ecologicamente correto, inclusive, porque eu compro muita coisa em brechó hoje em dia (A politizada).

[...] eu decidi que vou ter menos coisas [...] porque eu prefiro comprar pouco e comprar melhor (A detalhista).

A customização e reutilização de peças segue a orientação do tipo "faça você mesmo", característica de um adepto da simplicidade voluntária (ELGIN, 20I2; SHAMA, 198I). Já a opção por ter menos coisas reflete o valor foco na sociedade, de Johnston e Burton (2003). Além da utilização de roupas provenientes de brechós (SILVA, 20I3), parte das consumidoras relatou que prefere doar as roupas, confirmando a forma de descarte preferida do simplificador (BALLANTINE; CREERY, 20I0), ou trocá -las entre amigos, conforme relatos: 
Só de fazer trocas entre amigas já muda o seu guarda-roupa todo (A espontânea).

[...] eu dou pra alguma entidade ou pra uma campanha do agasalho, ou quando levo numa igreja que tem aqui no centro da minha cidade [...] (A equilibrada).

A categoria "Olhar crítico" demonstrou o interesse das entrevistadas em buscar peças de alta qualidade e durabilidade, e em quantidade limitada. Elas passaram a dar mais atenção à compra de roupas de forma mais criteriosa, como exemplifica o depoimento:

[...] como eu tenho poucas peças, eu presto mais atenção em caimento, corte, tecido, durabilidade ( $A$ detalhista).

Ao que parece, a adoção do conceito pelas consumidoras está associada às práticas de consumo de vestuário típicas da simplicidade voluntária. As formas de aquisição de roupas, suas características, e a maneira pela qual são descartadas, sugerem que as adeptas desse conceito apresentam semeIhanças com os adeptos do estilo de vida simples, de acordo com o quadro resumo:

A adoção do armário-cápsula resultou em uma série de reflexões sobre o significado da simplicidade para entrevistadas, descritas a seguir.

\section{A extensão da simplicidade}

Observou-se que as visões das adotantes do armário-cápsula sobre o que significa vi- ver com simplicidade são distintas, embora possuam elementos em comum. Para algumas entrevistadas, viver com simplicidade significa viver com poucas coisas, querer pouco e precisar de pouco, ou viver com o necessário, conforme os relatos ilustram:

Eu acho que viver com simplicidade é querer pouco, precisar de pouco ( $A$ politizada).

Viver com simplicidade é viver com o necessário pra sua existência ( $A$ empolgada).

Viver com poucas coisas, e úteis (A planejadora).

Outras respondentes afirmaram que, além da ideia de viver com menos, o estilo de vida simples é capaz de tornar a vida mais prática e proporcionar mais tempo para as pessoas desfrutarem das demais atividades do dia-a-dia.

Acho que viver de uma maneira mais prática, porque eu sou bem bagunceira, então menos coisas, de maneira mais simples (A desorganizada).

Se permitir ter menos coisas, viver com o que tu precisa mesmo, [...] ter mais tempo pra aproveitar o que tu tem (A equilibrada).

Os relatos acima condizem com a perspectiva de Johnston e Burton (2003) sobre o significado da simplicidade voluntária para os seus adeptos. De acordo com os autores, os simplificadores buscam viver

QUADRO 3 - Comparativo de consumo: adeptos da SV $\mathrm{x}$ adeptas do AC

\begin{tabular}{|c|c|}
\hline $\begin{array}{c}\text { Adeptos da Simplicidade Voluntária } \\
\text { (BALLANTINE; CREERY, 2010; ELGIN, 2012; JOHNSTON; } \\
\text { BURTON, 2003; SHAMA, 1981; SILVA, 2013) }\end{array}$ & Adeptas do Armário-Cápsula \\
\hline Preferência pela doação & A doação é a principal forma de descarte de peças \\
\hline Preferência por compras em brechós & Compram roupas em brechós \\
\hline Preferência por comprar e consumir menos & Compram e consomem menos \\
\hline Orientação do tipo "faça você mesmo" & Reutilizam e customizam peças \\
\hline Preferência pela durabilidade, funcionalidade e boa qualidade & Compram roupas mais duráveis, funcionais e de alta qualidade \\
\hline
\end{tabular}

Fonte: Elaborado pelos autores (2017). 
com pouco e querem menos posses, eles também buscam viver com o necessário e reduzir excessos (BEKIN; CARRIGAN; SZMIGIN, 2005), um indicativo do valor simplicidade material de Elgin e Michell (1977). Além disso, Luhrs (2002) considera que o estilo de vida simples é uma forma de ganhar tempo para si mesmo em um mundo agitado, em consonância com o último depoimento destacado.

A categoria "Simplicidade e Escolha" revelou outro aspecto evidenciado pelas respondentes: a noção de que a simplicidade não está vinculada a privações de consumo (ETIZIONI, I999), mas, na verdade, está ligada a uma escolha voluntária. A categoria "Simplicidade e Experiências" representou a simplicidade não como uma privação, mas uma maneira de repensar padrões de consumo, uma vez que as entrevistadas relataram valorizar mais o consumo de experiências do que a compra de bens e utensílios, conforme os depoimentos:

Em termos de posse, sim. Não uma privação, mas por uma escolha própria. Em nível de consumo também (A espontânea).

[...] eu acho que a gente pode investir em outras coisas, tipo experiências, viagens, a gente mesmo, do que com coisas pequenas ( $A$ desorganizada).

A preferência pelo consumo de experiências é um resultado consonante com o entendimento de Silva (20l3), onde foi argumentado que o consumidor simples valoriza mais o consumo de serviços, como viagens, cinema, restaurantes, atividades culturais, dentre outras experiências, do que o consumo de bens materiais.

A categoria "Consciência Ecológica” associou a percepção do estilo de vida simples a uma forma de consciência ecológica.
Esta consciência se manifesta através da preocupação com o meio-ambiente e com a percepção de que o consumo afeta a forma como a sociedade vive, de modo similar ao identificado nos adeptos da simplicidade voluntária (EHRLICH; EHRLICH, 1990). Na visão das entrevistadas, algumas das formas de ajudar a reduzir impactos ecológicos seriam: consumir menos, evitar o uso de materiais nocivos ao ambiente, utilizar menos plástico; preocupar-se com a origem dos produtos que são consumidos, além das suas formas de descarte.

E eu acho que cada vez mais vão ter pessoas se dando conta disso, que a gente precisa consumir menos até pra gerar menos lixo e que a gente não vive de uma forma sustentável, né? (A equilibrada).

[...] procurar usar menos plástico e materiais nocivos ao ambiente, consumir menos também (A planejadora).

Eu acho que a gente tem que se conscientizar do que a gente compra, da origem disso, e de como isso vai ser utilizado depois [...] (A autorreflexiva).

Ademais, adotar práticas que reduzam a sua dependência das organizações, como fazer seu próprio alimento em vez de comprá-lo pronto, além da preferência por mercados locais, características típicas dos valores autodeterminação e escala humana sugeridos por Elgin e Michell (1977).

Quer fazer um bolo? Faça o bolo em casa, não faz sentido você num bolo que você tem a receita. É ter conhecimento de base para você conseguir fazer as suas coisas. Preferir fazer o suco de frutas mesmo [...] (A espontânea).

Por exemplo: em vez de eu ficar indo em mercados de marca, assim. Com mais status [...] eu vou na feira de domingo do meu bairro, entendeu? (A criteriosa) 
A categoria "Crescimento Pessoal" evidenciou a busca pelo equilíbrio entre o crescimento profissional e o fortalecimento dos relacionamentos afetivos manifestada pelas respondentes. Para as adeptas do armário-cápsula, esse crescimento pessoal pode ser atingido por meio da melhoria contínua do indivíduo, da busca por viver de acordo com seus princípios, equilibrando relacionamentos. A categoria "Investimento Pessoal" mostrou que o investimento em coisas que o indivíduo gosta de fazer, em carreira, cursos e aperfeiçoamento de habilidades também é uma forma de se atingir um crescimento pessoal, como se observa abaixo:

[...] é um equilíbrio entre você descobrir uma coisa que tu gosta de fazer profissionalmente com tu tá de acordo, viver de acordo com teus princípios, com aquilo que você acredita, entre tu ter um equilíbrio nos teus relacionamentos, conseguir ter tempo e atenção pra cultivar os relacionamentos, as amizades (A equilibrada).

[...] é você investir em cursos e estudar outras línguas, aperfeiçoar habilidades (A detalhista).
A categoria "Crescimento Pessoal" representa, simultaneamente, dois valores propostos por Johnston e Burton (2003): foco nos relacionamentos e foco no self. $O$ primeiro sugere a simplificação da vida para uma maior dedicação à família, amigos ou à comunidade. Trata-se de um valor relativo à busca pelo equilíbrio entre a vida pessoal e profissional dos adeptos da simplicidade voluntária, que passam a priorizar as relações afetivas, em detrimento das obrigações profissionais. Já o foco no self visa à manutenção de valores pessoais essenciais, satisfação de vida e crescimento pessoal. Além disso, expressa a dimensão emocional (zelo aos relacionamentos), proposta por Elgin (20I2) para um simplificador, enquanto a categoria "Investimento Pessoal" revela que as respostas também foram compatíveis com a dimensão mental (buscar aprender continuamente). $O$ quadro a seguir resume os valores encontrados:

\section{CONSIDERAÇÕES FINAIS}

O armário-cápsula é um conceito adotado por consumidores que pretendem reduzir os seus padrões de consumo de roupas,

QUADRO 4 - Valores de SV identificados nas adeptas do AC

\begin{tabular}{|c|l|}
\hline $\begin{array}{c}\text { Valores de Simplicidade Voluntária } \\
\text { (JOHNSTON; BURTON, 2003; ELGIN, 2012; } \\
\text { ELGIN; MICHELL, 1977) }\end{array}$ & \\
\hline Foco nos relacionamentos & Buscam equilibrar relacionamentos, dedicar tempo e atenção à eles \\
\hline Foco no self & $\begin{array}{l}\text { Buscam viver de acordo com princípios, crescimento pessoal, satisfação de } \\
\text { vida, e desejam independência sobre suas escolhas e ações }\end{array}$ \\
\hline Foco na sociedade & Buscam reduzir o consumo \\
\hline Simplicidade material & Passam a consumir o que precisam, o necessário \\
\hline Consciência ecológica & $\begin{array}{l}\text { Se preocupam com o planeta, a sustentabilidade, com como seus padrões de } \\
\text { consumo afetam o ambiente }\end{array}$ \\
\hline Escala humana & Preferem mercados locais, menores, em vez de mercados de marca \\
\hline Autodeterminação & $\begin{array}{l}\text { Buscam reduzir a dependência das organizações optando por produzir o próprio } \\
\text { alimento em vez de comprá-lo pronto }\end{array}$ \\
\hline
\end{tabular}

Fonte: Elaborado pelos autores (2017). 
calçados e acessórios. Pretendeu-se com este estudo analisar esse fenômeno sob o olhar de um dos movimentos de resistência ao consumo, denominado de simplicidade voluntária. Especificamente, objetivou-se analisar aspectos da simplicidade voluntária no processo de adoção do conceito do armáriocápsula pelo público feminino. Diante do que foi exposto nos tópicos anteriores, algumas considerações podem ser apresentadas.

Em primeiro lugar, buscou-se compreender o que motivou as consumidoras a adotarem o armário-cápsula. Foram encontrados indícios de que valores da simplicidade voluntária, como o foco no self (JOHNSTON; BURTON, 2003) e a consciência ecológica (ELGIN; MICHELL, 1977), foram preponderantes para a adoção do conceito. Para as entrevistadas, a autonomia nas decisões de compra foi manifestada na oposição às pressões da indústria da moda e de seus amigos em prol da compra de peças duráveis e que possuíam um significado relevante para elas. Desta forma, a sensação de liberdade em relação à tais pressões (SILVA, 20I3), uma das razões que levariam um indivíduo a aderir à simplicidade voluntária, motivou as consumidoras a adotarem o armário-cápsula. Outra motivação foi a necessidade de repensar o consumo, devido à insatisfação com o consumismo. Ao que parece, as entrevistadas refletiram sobre o estimulo ao excesso promovido por uma cultura de consumo dominante (GRIGSBY, 2004), optando pela redução de consumo e pelo consumo mais simples, assim como os simplificadores (JOHNSTON; BURTON, 2003; SHAW; NEWHOLM, 2002). Também foi mencionado que as roupas das entrevistadas não as representavam, além de ocuparem excessivo espaço no guarda-roupa.
Em segundo lugar, no que diz respeito à adoção do conceito, foi constatado que as entrevistadas utilizam armários anuais, semestrais ou trimestrais com um número de peças flexível, desde que reduzido, dando ênfase à usabilidade e durabilidade das peças, elementos vinculados à simplicidade voluntária (ALEXANDER, 20 I I; ELGIN, 20 I0).A opção por ter menos roupas evidenciou o valor foco na sociedade, de Johnston e Burton (2003), uma vez que elas manifestaram um traço típico do estilo de vida simples: a redução do consumo (MCDONALD et al., 2006). Quanto à reposição de peças, a gestão do armário ocorreu por meio de compras com foco na substituição de peças (PUCCINI; ROBIC, 20I5). Percebeu-se que o armário-cápsula não se limitou a uma coleção de roupas para cada estação do ano, como afirmou Dougher (20 I5), pois participantes que residem em regiões onde as estações do ano não são bem definidas adotaram o conceito.

De maneira similar aos adeptos da simplicidade voluntária, as entrevistadas relataram a incorporação de novos hábitos de consumo em função da adoção do armário-cápsula, como a preferência por customizar peças e comprar itens em brechós, procurar ter menos coisas, comprar pouco e melhor, e optar pela doação como principal forma de descarte (BALLANTINE; CREERY, 20I0; ELGIN, 20I2; SHAMA, I98I; SILVA, 20 I 3).

Observou-se, por fim, que a visão de simplicidade das entrevistadas se assemelhou a dos adeptos da simplicidade voluntária, pois consideraram que uma vida simples tem relação com viver com o necessário (BEKIN; CARRIGAN; SZMIGIN, 2005), com pouco e querendo pouco (JOHNSTON; BURTON, 2003), um indicativo do 
valor simplicidade material de Elgin e Michell (1977).

Para as adeptas do armário-cápsula, a simplicidade representou uma escolha, não uma privação de consumo (ETIZIONI, 1999), e uma maneira de repensar padrões de consumo. Além disso, foi percebida como uma forma de buscar o equilíbrio e o fortalecimento dos relacionamentos afetivos, típico do foco nos relacionamentos (JOHNSTON; BURTON, 2003). As dimensões emocional e mental buscadas por um simplificador (ELGIN, 20I2) foram identificadas nas entrevistadas, bem como o valor consciência ecológica, através da preocupação com o meio-ambiente e como padrões de consumo afetam o planeta. Foi identificada, ainda, uma valorização do consumo de experiências, assim como a dos adeptos da simplicidade voluntária (SILVA, 20I3).

Os valores autodeterminação e escala humana (ELGIN; MICHELL, 1977), embora não atrelados à adoção do armário-cápsula, também surgiram em depoimentos sobre práticas de consumo mais independentes das empresas e a preferência por mercados menores e locais, respectivamente.

Percebeu-se, portanto, que a valorização do consumo de experiências e tendências de consumo da SV foram incorporadas pelas entrevistadas no processo de adoção do $A C$, além dos seguintes valores: foco na sociedade, consciência ecológica, foco no self, foco nos relacionamentos, simplicidade material. Ademais, a identificação dos valores autodeterminação e escala humana nos depoimentos sugeriram que as entrevistadas apresentaram afinidades com outros valores dos adeptos do estilo de vida simples, além daqueles identificados no processo de adoção do conceito.

No que diz respeito às contribuições acadêmicas desta pesquisa, cabe ressaltar que novas formas de consumo em consonância com a simplicidade voluntária estão surgindo e sendo difundidas em redes sociais virtuais. Desta forma, este estudo contribui para a literatura sobre movimentos de resistência ao consumo por analisar de forma pioneira um conceito que, apesar de ter sido criado da década de 1970, vem sendo difundido nos últimos anos e ganhando adeptos no Brasil.

Além disso, estudos anteriores relativos à simplicidade voluntária investigaram o fenômeno de forma mais abrangente, sem considerar a redução de consumo de produtos específicos (FERRAZ et al., 20I4; SILVA, HOR-MEYLL, 20I6). Neste sentido, a pesquisa se vincula a outras investigações que analisaram movimentos de resistência ao consumo de produtos específicos, como o estudo de Suarez, Chauvel e Casotti (20I2). Contudo, futuras investigações podem verificar a adoção de outros movimentos de resistência ao consumo que estejam vinculados à indústria da moda. Também é possível investigar o olhar das empresas para a difusão de conceitos como o do armário-cápsula. $\mathrm{A}$ indústria da moda brasileira se preocupa com estes movimentos? Pretende adotar estratégias para satisfazer tais consumidores? Novas pesquisas podem considerar estes questionamentos, assim como analisar a adoção do armário-cápsula pelo público masculino. 
ALEXANDER, Samuel. et al. Voluntary simplicity: the poetic alternative to consumer culture. Stead \& Daughters, 2009.

The voluntary simplicity movement: reimagining the good life beyond consumer culture. The International Journal of Environmental, Cultural, Economic \& Social Sustainability, v. 7, n. I, p.4-20, 2011.

AQUINO, José Felipe Pazos. 0 “Eu Estendido" e a adoção da simplicidade voluntaria. 2016. 94 f. Dissertação (Mestrado em Administração) - Universidade Católica do Rio de Janeiro, Rio de Janeiro, 2016.

AUDET, Denis; SAFADI, Raed. A new world map in textiles and clothing adjusting to change: adjusting to change. [s.i.]: Oecd Publishing, 2004.

BALLANTINE, Paul W.; CREERY, Sam. The consumption and disposition behaviour of voluntary simplifiers. Journal of Consumer Behaviour, [s.I.], v. 9, n. I, p.4556, jan. 2010. Wiley-Blackwell. http://dx.doi.org//0.1002/cb.302.

BARDIN, Laurence. Análise de Conteúdo. São Paulo: Ed. 70. Almedina Brasil, 20 I I.

BARROS, D. F. et al. The production and dissemination of conscious consumption discourse in Brazil. Advances in Consumer Research, v. 37, p. I-2, 2009.

BARTON, Katherine M. Listening to the quiet revolution: the implications of voluntary simplicity for a sustainable society. 2015. 89 f. Tese (Doutorado em Arts, Environmental Analysis) - Pomona College, [s.i.], 2015.

BAUMAN, Zygmunt. Vida para consumo. Zahar, 2008.
BEKIN, Caroline; CARRIGAN, Marylyn; SZMIGIN, Isabelle. Defying marketing sovereignty: voluntary simplicity at new consumption communities. Qualitative Market Research: An International Journal, [s.l.], v. 8, n. 4, p.4I3-429, dez. 2005. Emerald. http://dx.doi. org/10.1 I08/135227505106/9779.

BORELLI, F. Consumo responsável sob a perspectiva prático-teórica: um estudo etnográfico em uma ecovila. Tese (Doutorado em Administração) - Instituto de PósGraduação e Pesquisa em Administração da Universidade Federal do Rio de Janeiro (COPPEAD/ UFRJ), Rio de Janeiro, 2014.

BYUN, Sang-eun; STERNQUIST, Brenda. Fast fashion and in-store hoarding. Clothing and Textiles Research Journal, [s.I.], v. 29, n. 3, p.187-20I, I4 jun. 201 I. SAGE Publications. http://dx.doi. org/ I0. I I77/0887302x I |4 I I 709.

CHAUVEL, Marie Agnes et al. Anticonsumo no brasil: reflexões sobre os estudos existentes e proposta de uma agenda de pesquisa. Facef Pesquisa: Desenvolvimento e Gestão, [s.I.], v. I8, n. I, p.5-23, 8 abr. 2015.

DOUGHER, Kelly. You're doing the "capsule wardrobe" wrong. 20I5. Disponível em: <http://fashionmagazine.com/ fashion/youre-doing-the-capsule -wardrobe-wrong/>. Acesso em: 0I jan. 2017.

EHRLICH, Paul R.; EHRLICH,Anne H. The population explosion. Simon and Schuster, 1990.

ELGIN, Duane. Voluntary simplicity: toward a way of life that is outwardly simple, inwardly rich. Harper Paperbacks, 1993. .The living uni- verse: where are we? who are we? where are we going? San Francisco: Berrett-koehler, 2010. Simplicidade

voluntária: em busca de um estilo de vida exteriormente simples, mas interiormente rico. 5. ed. São Paulo: Cultrix, 2012.

ELGIN, Duane; MITCHELL, Arnold. Voluntary Simplicity. The CoEvolution Quarterly, Summer, n. 14. p. 4-18, 1977.

ETZIONI, Amitai. Voluntary simplicity: characterization, select psychological Implications, and societal consequences. Studies in Economic Ethics and Philosophy, [s.l.], p.l-26, 1999. Springer Berlin Heidelberg. http://dx.doi. org/l 0.1007/978-3-662-039007 I.

FERRAZ, Sofia Batista et al. Ser ou não ter, eis a questão: um estudo sobre materialismo e estilo de vida. Revista de Administração da Ufsm, [s.l.], v. 7, p.23-42, 3 abr. 2014. Universidade Federal de Santa Maria. http://dx.doi. org/l0.5902/19834659/280I.

GAMBREL, Joshua Colt; CAFARO, Philip. The virtue of simplicity. Journal of Agricultural and Environmental Ethics, [s.I.], v. 23, n. 1-2, p.85-108, 17 jun. 2009. Springer Nature. http://dx.doi. org/10.1007/s 10806-009-9/87-0.

GRIGSBY, M. Buying time and getting by: the voluntary simplicity movement. State University of New York Press, Albany, 2004.

HEGER, Giuliana. The capsule closet phenomenon: a phenomenological study of lived experiences with capsule closets. 2016, 67 f. Tese (Doutorado em Fashion Management) - The Swedish School Of Textiles - University Of Borås, [s.i.], 2016. 
IYER, Rajesh; MUNCY, James A. Purpose and object of anti-consumption. Journal of Business Research, [s.l.], v. 62, n. 2, p.160-168, fev. 2009. Elsevier BV. http://dx.doi.org/10.1016/j.jbusres.2008.01.023.

JOHNSTON, Timothy C.; BURTON, Jay B.. Voluntary simplicity: definitions and dimensions. Academy of Marketing Studies Journal, Cullowhee, v. 7, n. I, p.19-36, nov. 2003.

KARG, Corinna. New fashion minimalism in an affluent society: a paradigm shift? 20I5. 90 f. Tese (Doutorado em Fashion Management) - The Swedish School Of Textiles - University Of Borås, [s.i.], 2017.

KUMAR, Ranjitha; VACCARO, Kristen. An experimentation engine for data-driven fashion systems. In: The Aaai 2017 spring symposium, 4., 2017, Illinois. Symposium. Illinois: Aaai Publications, 2017. p. 389 - 394.

KOZINETS, R.V.; HANDELMAN, J.M.; LEE, M.S.W. Don't read this; or, who cares what the hell anti-consumption is, anyways? Consumption Markets \& Culture, v. I3, n. 3, p. 225-233, 2010.

LUHRS, J.. The best of simplicity and more. 2002. Disponível em: <http://www.SimpleLiving.com>. Acesso em: 19 abr. 2017.

MCDONALD, Seonaidh et al.Toward sustainable consumption: researching voluntary simplifiers. Psychology and Marketing, [s.l.], v. 23, n. 6, p.5I5-534, 2006. Wiley-Blackwell. http://dx.doi. org/10.1002/mar.20132.

MERRIAM, S. Qualitative research: a guide to design and implementation. New York: Jossey-Bass, 2009. MONTEIRO, Plínio Rafael Reis et al. Personalidade e consumo ecologicamente consciente. Revista de Administração Faces Journal, [S.I.], v. 7, n. 2, p.20-49, abr. 2008.

NEPOMUCENO, M. V. Anti-consumption: the lifestyles of the disciplined materialists. 20I2. Tese (Doutorado em Filosofia - Administração) - John Molson School of Business. Concordia University. Montreal, 2012.

PIERCE, Linda Breen. Choosing simplicity: real people finding peace and fulfillment in a complex world. [s.i.]: Gallagher Press, 2000.

PUCCINI, Camila; ROBIC, André. Lowsumerism: o consumo consciente no mercado da moda. In: XI Semana de Extensão, Pesquisa e Pós-Graduação - SEPESQ, II., 20I5, Anais... Porto Alegre, 2015.

RECTOR, Caroline. Capsule wardrobe planner. 2014. Disponível em: <http://www.un-fancy.com/ wp-content/uploads/20 | 4/06/ capsuleplanner_-UPDATED.pdf>. Acesso em: 20 jan 2017.

SEGAL, Jerome M. Graceful simplicity: toward a philosophy and politics of simple living. Hardcover, 1999.

SHAMA, Avraham. Coping with staglation: voluntary simplicity. Journal of Marketing, [s.I.], v. 45, n. 3, p. I 20- I 34, jun. I 98।.JSTOR. http:// dx.doi.org/ / 0.2307// 25 I 547.

SHAW, Deirdre; NEWHOLM, Terry. Voluntary simplicity and the ethics of consumption. Psychology \& Marketing, [s.l.], v. 19, n. 2, p. I67-I85, I 7 jan. 2002.Wiley-Blackwell. http://dx.doi.org//0.1002/ mar. 10008.

SHI, David E.. The simple life: plain living and high thinking in american culture. University of Georgia Press, 1985.

SILVA, Renata Celí Moreira da. Simplicidade voluntária: um estudo exploratório sobre a adoção de um novo estilo de vida e seus impactos sobre o consumo. 2013. I 59 f. Tese (Doutorado em Administração) - Pontifícia Universidade Católica do Rio de Janeiro, Rio de Janeiro, 2013.

HOR-MEYLL, Luis Fernando; SILVA, Renata Celi Moreira da. Simplicidade voluntária: escolhendo uma nova forma de viver. Revista Pretexto, [s.l.], v. I7, n. 2, p.98I 16, 30 ago. 2016. ANPAD. http:// dx.doi.org/| 0.2 I 7/4/pretexto. v17i2.3772.

SOUZA, Maria Cecília Galli Lugnani; CASOTTI, Letícia Moreira; LEMME, Celso Funcia. Consumo consciente como determinante da sustentabilidade empresarial: respeitar os animais pode ser um bom negócio? Revista de Administração da Ufsm, [s.l.], v. 6, p.229-245, 2 jul. 20 I3. Universidad Federal de Santa Maria. http://dx. doi.org/l 0.5902/I98346599022.

SUAREZ, Maribel; CHAUVEL, Marie Agnes; CASOTTI, Leticia. Motivações e significados do abandono de categoria: aprendizado a partir da investigação com exfumantes e ex-proprietários de automóveis. Cadernos Ebape. br, [s.I.], v. I0, n. 2, p.4 I I-434, jun. 20I2. Fap UNIFESP (SciELO). http://dx.doi.org//0.1590/s I67939512012000200010.

SOPER, Kate. Alternative hedonism, cultural theory and the role of aesthetic revisioning. Cultural Studies, [s.l.], v. 22, n. 5, p.567-587, set. 2008. Informa UK Limited. http://dx.doi. org/10.1080/09502380802245829.

TONI, Deonir de; LARENTIS, Fabiano; MATTIA, Adilene. Consumo consciente, valor e lealdade em produtos ecologicamente corretos. Revista de Administração Faces Journal, [S.I.], v. I I, n. 3, p.|36-I56, jul. 2012.

TRINDADE, Talita de Oliveira; 
AYROSA, Eduardo André Teixeira; SAUERBRONN, João Felipe Rammelt. Consumption and resistance in the context of brazilian housewives and consumers' movement. Sociedade, Contabili- dade e Gestão, [s.I.], v. I0, n. 3, ZAVESTOSKI, Stephen. The social-psyp.I05-II7, 27 jun. 2016. Programa de Pos-graduacao em Ciencias Contabeis da UFRJ. http:// dx.doi.org/ 0.2 I 446/scg_ufrj. vI0i3.13364. chological bases of anticonsumption attitudes. Psychology and Marketing, [s.l.], v. 19, n. 2, p.149-165, 17 jan. 2002. Wiley-Blackwell. http://dx. doi.org/10.1002/mar.10007. 